\title{
Isogenic mutants of the cag pathogenicity island of Helicobacter pylori in the mouse model of infection: effects on colonization efficiency
}

\author{
Marta Marchetti† and Rino Rappuoli
}

Immunobiological Research Institute of Siena (IRIS) Chiron Spa, Via Fiorentina 1, 53100 Siena, Italy
Author for correspondence: Marta Marchetti. Tel: +3314568 86 79. Fax: +33140613713. e-mail: mmarchet@pasteur.fr

\begin{abstract}
Strains of Helicobacter pylori that contain the cag pathogenicity island (cag PAI) are associated with increased virulence and severe clinical outcomes. To evaluate the role of the cag island in infection, isogenic null mutations were generated in two clinical isolates (SS1 and Iris1) with distinct genetic backgrounds. When tested for their ability to establish infection in the stomach of CD1/SPF mice, at the early phase of infection, strains in which cagE, ORF528, ORF527 or ORF525 were inactivated showed a reduced capacity to initiate colonization compared to the wild-type strain. Strains with a mutation in the ORF524 gene were more efficient than the other mutants, but still less efficient than the wild-type strain. Mutation in the effector protein, CagA, which is injected into host cells and tyrosine-phosphorylated, did not change the colonization efficiency. In conclusion, all cag genes analysed, with the exception of the effector protein, CagA, influenced the early phase of colonization in the mouse model of infection. These results suggest that the structure of the $\boldsymbol{H}$. pylori secretion apparatus itself is involved in this process.
\end{abstract}

Keywords: virulence, type IV secretion system, gastric pathogen

\section{INTRODUCTION}

The micro-aerophilic, rod-shaped gastric pathogen Helicobacter pylori causes gastritis, peptic ulcers and increases the risk of developing gastric tumours in humans (Parsonnet et al., 1991; Blaser, 1992; Mitchell, 1993; Logan, 1994; NIH consensus 1994). Genetic analysis of $H$. pylori revealed the presence of a pathogenicity island (PAI) named cag in the genome of a subset of strains (Censini et al., 1996; Akopyants et al., 1998). It has been shown that patients with overt clinical outcomes are infected with strains carrying the cag PAI (type I strains) and that strains that lack the cag PAI (type II strains) are responsible for milder clinical outcomes (Telford et al., 1994; Marchetti et al., 1995). In vitro experiments showed that the cag PAI plays an important role in enhancing bacterial virulence. Fol-

† Present address: Department of Bacteriology and Mycology, Laboratory of Lympho-Epithelial Interactions, Pasteur Institute 28, rue du Dr Roux, 75015 Paris Cedex 15, France.

Abbreviation: PAl, pathogenicity island. lowing intimate contact between the host cell and the pathogen, cag induces the secretion of IL-8 from eukaryotic cells and activates the nuclear transcriptional factor NF- $\kappa \mathrm{B}$ (Censini et al., 1996; Segal et al., 1997; Akopyants et al., 1998; Glocker et al., 1998). In addition, it has been shown that impairment of IL-8 secretion may affect bacterial colonization efficiency in Balb/c mice (van Doorn et al., 1999). However, no causal relationship between the absence of IL-8 induction and the ability of higher colonization efficiency can be concluded since this observation seems restricted to the particular aplotype of $\mathrm{Balb} / \mathrm{c}$ mice.

It has been shown that six cag genes encode proteins that are homologous to components of the multiprotein complexes involved in the bacterial conjugation-transport system (type IV secretion system). These include the vir operon of Agrobacterium tumefaciens, the $p t l$ transporter apparatus of Bordetella pertussis and the tra system of Escherichia coli (Reeves et al., 1994; Christie, 1997; Winans et al., 1996; Zupan et al., 1998; Hacker et al., 1997; Weiss et al., 1993; Censini et al., 1996). Other VirB homologues have been identified in Brucella suis 
and Legionella pneumophila, and are important for the infection of human macrophages in vitro (O'Callaghan et al., 1999) and for the transfer of plasmid DNA (Vogel et al., 1998; Segal \& Shuman, 1999), respectively. In addition to these homologies, it has been shown that cag is necessary for the transfer of the CagA protein into epithelial gastric cells in vitro (Segal et al., 1999; Odenbreit et al., 2000; Stein et al., 2000), which further indicates that cag encodes a secretion apparatus that contributes to $H$. pylori virulence. It has been shown that mice can be experimentally infected by fresh clinical isolates of $H$. pylori (Karita et al., 1991; Marchetti et al., 1995; Lee et al., 1997). This model has been extensively used because it reproduces human $H$. pylori-associated gastric disease (Marchetti et al., 1995; Lee, 1998). Central to this study has been the use of this in vivo assay, the mouse model of infection, as a biological filter to test the importance of $c a g$ in the initial step of gastric colonization. We used two recipient type I H. pylori strains to construct defined isogenic mutants missing components of the secretion apparatus, i.e. cagE (homologous to virB4), ORF528 (homologous to virB9), ORF527 (homologous to virB10), ORF525 (homologous to virB11), ORF524 (homologous to virD4) and the secreted CagA protein. Each gene was deleted individually and the mutants were analysed for their ability to colonize the stomach of mice during the early stages of colonization.

\section{METHODS}

$\boldsymbol{H}$. pylori strains and culture conditions. $H$. pylori strain Iris1 was recovered from human gastric biopsies obtained from the Medical Pathology Department, Siena Hospital, Siena, Italy. The strain was analysed for the presence of cag PAI by PCR analysis and tested for its ability to infect mice. The primers used to analyse the structure of the cag PAI are listed in Table 1. PCR amplification was performed under standard conditions. The vacA gene was analysed by sequencing the midregion ( $\mathrm{m} 1$ and $\mathrm{m} 2$ ) as described by Atherton et al. (1995) and Pagliaccia et al. (1998). H. pylori strain SS1 is an Australian type I strain obtained by Dr A. Lee (University of New South Wales, Australia) and capable of colonizing the gastric mucosa of mice at high density (Lee et al., 1997). These strains were used to obtain isogenic mutants for infection experiments. $H$. pylori CCUG 17874 was obtained from the University of Gotheberg and used as a representative laboratory strain that is unable to colonize mice. Table 2 shows the phenotypic and genotypic characteristics of these three strains. Bacteria were grown on Columbia agar plates supplemented with $10 \%$ horse blood plus vancomycin $\left(10 \mu \mathrm{g} \mathrm{ml}^{-1}\right)$, cefsulodin $(5 \mu \mathrm{g}$ $\left.\mathrm{ml}^{-1}\right)$, polymyxin $\mathrm{B}\left(2 \cdot 5 \mathrm{U} \mathrm{ml}^{-1}\right)$, cyclohexamide $\left(50 \mu \mathrm{g} \mathrm{ml}^{-1}\right)$, trimethoprim $\left(5 \mu \mathrm{g} \mathrm{ml}^{-1}\right)$, amphotericin $\mathrm{B}\left(8 \mu \mathrm{g} \mathrm{ml}^{-1}\right), \beta$-cyclodextrin $(0 \cdot 2 \%)$ and bacitracin $\left(200 \mu \mathrm{g} \mathrm{ml}^{-1}\right)$ using the Anaereojar system with the Campygen atmosphere-generating system (Oxoid). For kanamycin-resistant bacteria, plates were supplemented with kanamycin $\left(20 \mu \mathrm{g} \mathrm{ml}^{-1}\right)$.

Animal colonization. Six 1-week-old CD1/SPF (SpecificPathogen-Free) male mice were purchased from Charles River and kept in a $12 \mathrm{~h}$ light/dark schedule in an air-conditioned animal facility. Water and food was provided ad libitum. Mice were fasted for $24 \mathrm{~h}$ immediately before inoculation and being sacrificed. Each mouse received $250 \mu$ l sodium bicarbonate oro-gastrically to neutralize gastric acid, according to the protocol described previously (Marchetti et al., 1995). Half an hour later, $1 \times 10^{9}$ c.f.u. bacteria in $150 \mu \mathrm{l}$ sterile PBS was administered to each mouse through the same route. As a control, a similar group of mice was inoculated with PBS alone. Mice were sacrificed by cervical dislocation at predetermined times and colonization was assessed. Animals were inoculated and cared for according to institutional guidelines.

Assessment of $\boldsymbol{H}$. pylori colonization. The stomach of sacrificed mice was removed and opened through the lesser curvature. The number of viable infecting bacteria was estimated by making serial dilutions of the homogenized tissue in sterile PBS and plating on blood agar plates supplemented with bacitracin alone or supplemented with specific selective antibiotics and incubated for $3-5$ days at $37^{\circ} \mathrm{C}$ in a microaerophilic jar. Growing bacteria were identified by Gramstaining and morphology. The remaining material was immediately frozen in liquid nitrogen and stored at $-80^{\circ} \mathrm{C}$ until required.

PCR on gastric samples. The frozen samples were defrosted and DNA was extracted as described by Clayton et al. (1991); $5 \mu \mathrm{l}$ of the recovered material was used for PCR with D008/R008 cagA-specific primers (Xiang et al., 1995; Table 1). Gene amplification was carried out in a Perkin-Elmer thermal cycler for 35 cycles. Each cycle consisted of a denaturation step at $94^{\circ} \mathrm{C}$ for $5 \mathrm{~min}$, a primer annealing step at $60{ }^{\circ} \mathrm{C}$ for $30 \mathrm{~s}$ and an extension step at $72{ }^{\circ} \mathrm{C}$ for $30 \mathrm{~s}$.

Construction of $\boldsymbol{H}$. pylori isogenic mutants. Isogenic SS1 and Iris1 cag $A$ mutants were obtained by natural transformation with the clone A plasmid obtained by Antonello Covacci (Chiron Vaccines) and described by Xiang et al. (1995). The other cag mutations were constructed by inserting a non-polar kanamycin resistance determinant, aphA-3' of Campylobacter coli, recovered using the PstI restriction site from a plasmid generously donated by Antonello Covacci (Chiron Vaccines). Primers (Table 3) were constructed by use of an Applied Biosystems synthesizer and the automated phosphoramidite coupling method. For each gene we used PCR to amplify two fragments containing $K p n \mathrm{I} / P s t \mathrm{I}$ and PstI/NotI restriction sites at the ends. These fragments were cloned into the $K p n \mathrm{I} /$ Not I site of pBluescript SK + (Stratagene). The kanamycin cassette was cloned into the PstI site of the gene. The final constructs were transformed into competent E. coli DH10B (Gibco BRL). Each recombinant plasmid (Table 2) was sequenced with an ABI Prism Dye Terminator Sequencing Kit (Applied Biosystems). The purified DNA was used to mutagenize the wild-type locus by allelic exchange with the recipient SS1 and Iris1 strains. The isogenic mutants were selected by plating on selective media. DNA was extracted from three colonies for each mutant and stored at $-80^{\circ} \mathrm{C}$. The extracted DNA was used for PCR analysis with primers listed in Table 4 to confirm the recombination event. A single recombinant clone for each mutant was then used for each infection experiment.

Production of fusion proteins and polyclonal antibodies. We used the H. pylori genome sequence to construct the fusion proteins for ORF528, ORF527, ORF525 and ORF524 (Tomb et al., 1997). Each of the fusion proteins was constructed by use of the QIA-expression system (Qiagen). Briefly, the hydrophilic region of each ORF [according to the KyteDoolittle analysis (Kyte \& Doolittle, 1982)] was amplified by PCR with specific primers (Table 5). The amplified fragments were cloned into the pQE30 expression vector containing a 
Table 1. Primers used to study the cag PAI structure

\begin{tabular}{|llcl|}
\hline Oligonucleotide & \multicolumn{1}{c|}{ Corresponding ORF } & Strand & \multicolumn{1}{c|}{ Sequence $\left(\mathbf{5}^{\prime}-\mathbf{3}^{\prime}\right)$} \\
\hline D008 & $c a g A$ & + & ATAATGCTAAATTAGACAACTTGAGCGA \\
R008 & $c a g A$ & - & TTAGAATAATCAACAAACATCACGCCAT \\
E1 & $c a g E$ & - & TCAAGCCTATGAACCTGTTTT \\
E2 & cagE & + & GTCTTCTCTGTTTGGATTTAAG \\
B1 & ORF525 & - & AACCATTTGATGTGAGAGACAG \\
B2 & ORF525 & + & GTTTCATCATTAACTGTAACAG \\
E64T & Middle zone (intervening sequence) & + & GATAACAGCGCGATAATCTTTCAT \\
HR6 & Middle zone (intervening sequence) & - & GTTTGATCAACGAGGCAATAGATT \\
9KPFa & ORF528 & - & CTCGGTAAAAAGT \\
9PNRb & ORF528 & + & AAAATTGCTCTTAGTTT \\
10KPFa & ORF527 & - & AACAGGAATGCGAG \\
10PNRb & ORF527 & + & CGCCACTATATCCTCTAGA \\
$4 \mathrm{KPFa}$ & ORF524 & - & CGGAAGACTTT \\
4PNRb & ORF524 & + & TTCGCTTGAACCCACAG \\
\hline
\end{tabular}

Table 2. Bacterial strains and plasmids used in this study

\begin{tabular}{|c|c|c|c|}
\hline Strain or plasmid & Genotype or phenotype & Characteristics & Reference or source \\
\hline \multicolumn{4}{|l|}{ H. pylori } \\
\hline CCUG 17874 & Type I; $c a g^{+} v a c A^{+}(\mathrm{m} 1)$ & $\begin{array}{l}\text { Laboratory strain, unable to } \\
\text { infect mice }\end{array}$ & Gotheberg \\
\hline SS1 & Type I; $c a g^{+} \mathrm{ORF}^{-} v a c A^{+}(\mathrm{m} 2)$ & $\begin{array}{l}\text { Competent for natural } \\
\text { transformation, able to infect } \\
\text { mice }\end{array}$ & $\begin{array}{l}\text { Lee et al. (1997); } \\
\text { Salama et al. (2000) }\end{array}$ \\
\hline Iris1 & Type I; $\mathrm{cag}^{+} \operatorname{vac}^{+}(\mathrm{m} 2)$ & $\begin{array}{l}\text { Fresh isolate, competent for } \\
\text { natural transformation, able to } \\
\text { infect mice }\end{array}$ & This study \\
\hline \multicolumn{4}{|l|}{ E. coli } \\
\hline DH10B & $\begin{array}{l}\mathrm{F}^{-} \operatorname{mrc} A \Delta \phi 80 \mathrm{~d} \text { lacZ } \Delta \mathrm{M} 15 \Delta \text { lacX74 deoR }(\text { ara leu }) 7697 \\
\text { recA1 endA1 araD139 galU galKd rpsL nupG rpsL } \lambda^{-}\end{array}$ & & Gibco BRL \\
\hline M15(pREP4) & $\begin{array}{l}\mathrm{Nal}^{\mathrm{s}} \mathrm{Str}^{\mathrm{s}} \mathrm{Rif}^{\mathrm{s}} \mathrm{Thi}^{-} \mathrm{Lac}^{-} \mathrm{Ara}^{+} \mathrm{Kan}^{\mathrm{r}} \mathrm{Gal}^{+} \mathrm{Mtl}^{-} \mathrm{F}^{-} \\
\mathrm{RecA}^{+} \mathrm{Uvr}^{+} \mathrm{Lon}^{+}\end{array}$ & & Qiagen \\
\hline \multicolumn{4}{|l|}{ Plasmids } \\
\hline pBluescript SK+ & pUC19-derived; ColE1 ori lacZ Amp ${ }^{\mathrm{r}}$; cloning vector & & Stratagene \\
\hline p9K9 & $\begin{array}{l}\text { pBluescript SK }+ \text { containing the ORF528 gene with the } \\
\text { aphA-3' } \text { Kan }^{r} \text { cassette inserted }\end{array}$ & & This study \\
\hline $\mathrm{p} 10 \mathrm{~K} 10$ & $\begin{array}{l}\text { pBluescript SK }+ \text { containing the ORF527 gene with the } \\
\text { aphA-3' } \operatorname{Kan}^{\mathrm{r}} \text { cassette inserted }\end{array}$ & & This study \\
\hline $\mathrm{p} 11 \mathrm{~K} 11$ & $\begin{array}{l}\text { pBluescript SK }+ \text { containing the ORF525 gene with the } \\
\text { aphA-3' } \text { Kan }^{\mathrm{r}} \text { cassette inserted }\end{array}$ & & This study \\
\hline $\mathrm{p} 4 \mathrm{~K} 4$ & $\begin{array}{l}\text { pBluescript SK + containing the ORF524 gene with the } \\
\text { aphA-3' } \operatorname{Kan}^{\mathrm{r}} \text { cassette inserted }\end{array}$ & & This study \\
\hline pQE30 & ColE1 ori bla $\mathrm{Amp}^{\mathrm{r}}$ lacZ $6 \times$ His tag; cloning vector & & Qiagen \\
\hline pQE9K9 & pQE30 containing the hydrophilic region of ORF528 & & This study \\
\hline pQE10K10 & pQE30 containing the hydrophilic region of ORF527 & & This study \\
\hline pQE11K11 & pQE30 containing the hydrophilic region of ORF525 & & This study \\
\hline pQE4K4 & pQE30 containing the hydrophilic region of ORF524 & & This study \\
\hline
\end{tabular}


Table 3. Oligonucleotide primers used for PCR, cloning and sequencing

Lower case letters in the primers sequences indicate cleavage recognition sequence. Underlining indicates sites for KpnI (GGTACC), Pst I (CTGCAG) and NotI (GCGGCCGC) that were added at the $5^{\prime}$ end to create restriction sites.

\begin{tabular}{|c|c|c|c|}
\hline Oligonucleotide & Corresponding ORF & Strand & Sequence $\left(\mathbf{5}^{\prime}-\mathbf{3}^{\prime}\right)$ \\
\hline EK & $\operatorname{cag} E$ & - & ccggGGTACCAATGGGCTTGTTTATACAAAT \\
\hline EPS & cagE & + & $\operatorname{tgcaCTGCAGACAAACACCTCTCTCTCTT~}$ \\
\hline EP & cagE & - & $\operatorname{tgca} \overline{\text { CTGCAGAGCTAATTATAGAGCAAGAG }}$ \\
\hline $\mathrm{EN}$ & $\operatorname{cag} E$ & + & ccttGCGGCCGCTAAGTGGATGTCATTAGCCAT \\
\hline 9KPF & ORF528 & - & ccggGGTACCTCGGTAAAAAGT \\
\hline 9KPR & ORF528 & + & 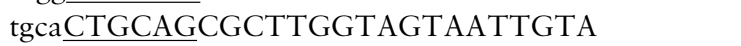 \\
\hline 9PNF & ORF528 & - & 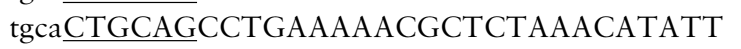 \\
\hline 9PNR & ORF528 & + & ccttGCGGCCGCAAAATTGCTCTTAGTTTCTGC \\
\hline $10 \mathrm{KPF}$ & ORF527 & - & ccggGGTACCAACAGGAATGCGAG \\
\hline 10KPR & ORF527 & + & tgcaCTGCAGTCGTCAATGGGATTACCATTTTCT \\
\hline 10PNF & ORF527 & - & 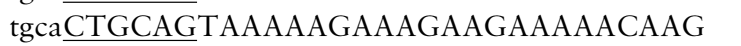 \\
\hline 10PNR & ORF527 & + & ccttGCGGCCGCCGCCACTATATCCTCTAGAAGA \\
\hline $11 \mathrm{KPF}$ & ORF525 & - & ccggGGTACCGTTTCAATG \\
\hline $11 \mathrm{KPR}$ & ORF525 & + & 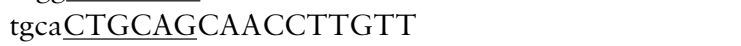 \\
\hline $11 \mathrm{PNF}$ & ORF525 & - & tgca $\overline{\text { CTGCAGGGCGAATGGCAACCATTTGATGTG }}$ \\
\hline 11PNR & ORF525 & + & ccttGCGGCCGCGGACAATCATATCAAATCAAAT \\
\hline $4 \mathrm{KPF}$ & ORF524 & - & ccggGGTACCGGAAGACTTT \\
\hline $4 \mathrm{KPR}$ & ORF524 & + & tgcaCTGCAGACATGAGATC \\
\hline 4PNF & ORF524 & - & tgca $\overline{\text { CTGCAGGGACTAAAAAGGGGCTTGAGTTTG }}$ \\
\hline 4PNR & ORF524 & + & ccttGCGGCCGCTTCGCTTGAACCCACAGGCACT \\
\hline
\end{tabular}

Table 4. Oligonucleotide primers designed to check for cag inactivation

\begin{tabular}{|lccl|}
\hline Oligonucleotide & $\begin{array}{c}\text { Corresponding } \\
\text { ORF }\end{array}$ & Strand & \multicolumn{1}{c|}{ Sequence $\left(\mathbf{5}^{\prime}-\mathbf{3}^{\prime}\right)$} \\
\hline AcloneF & cagA & + & ATCCTCTCGTTTCCTTAGAGA \\
AcloneR & cagA & - & CACAGGCAATTATGATGAAGT \\
EPCRF & cagE & - & ACATATTAGCACCGTAGAGTC \\
EPCRR & cagE & + & TGTTCATCATCAGCCTGCTGCT \\
9FTEST & ORF528 & - & AGTGAATGTGCCATCATCAA \\
9RTEST & ORF528 & + & CAATATGTGCATAATGCATT \\
10FTEST & ORF527 & - & GGCCTGTTTGACAGGGCTTGT \\
10RTEST & ORF527 & + & AAATATCAGTGAAATCGCTCTTA \\
11FTEST & ORF525 & - & GGCTTTCCTGTCTCTCACAT \\
11RTEST & ORF525 & + & ACTGAGATTTGTTACAATGG \\
4FTEST & ORF524 & - & TTTGACAAACTCAAGCCCCT \\
4PCRR & ORF524 & + & TAGCAATCAAGCGCGAAATCT \\
\hline
\end{tabular}

$6 \times$ His affinity tag and electroporated into the K12 derivative E. coli M15(pREP4) (Table 2) (Villarejo \& Zabin, 1974). IPTG was added to induce the expression of the recombinant proteins and the fusion protein was purified by binding the affinity tag to Ni-NTA resin. Polyclonal antibodies were obtained from rabbits immunized with each of the purified recombinant proteins $(50 \mu \mathrm{g}$ per dose + MF59, four doses), according to standard protocols, and used for Western blot analysis. Wild-type and mutant $H$. pylori strains were grown on blood agar plates, recovered in PBS and boiled in the presence of SDS-PAGE loading buffer. The bacterial lysates were then used for Western blot analysis. Antisera (diluted $1: 5000)$ and a peroxidase-labelled goat anti-rabbit $\operatorname{IgG}(\mathrm{H}+\mathrm{L})$ (Gibco BRL) were used for SDS-PAGE immunoblot analysis. The immunoblot was developed by the ECL Western blotting detection system (Amersham).

Bacterial transformation. All the H. pylori mutants were obtained following the transformation protocol described by Copass et al. (1997). Briefly, bacteria were grown on blood agar plates for $48 \mathrm{~h}$ and then streaked onto fresh non-selective plates and incubated for $6 \mathrm{~h}$. DNA $(1 \mu \mathrm{g})$ was then mixed with the growing bacteria. Plates were incubated for a further $16 \mathrm{~h}$ 
Table 5. Oligonucleotide primers designed to obtain fusion proteins

Underlined sequences indicate sites for KpnI (GGTACC) and PstI (CTGCAG). Lower case letters indicate the cleavage recognition sequence.

\begin{tabular}{|lcccl|}
\hline Oligonucleotide & $\begin{array}{c}\text { Corresponding } \\
\text { ORF }\end{array}$ & Strand & $\begin{array}{c}\text { Position on the } \\
\text { reference sequence* }\end{array}$ & Sequence $\left(\mathbf{5}^{\prime} \mathbf{- \mathbf { 3 } ^ { \prime } )}\right.$ \\
\hline 9BPF & ORF528 & - & 17713 & cggGGTACCTCGGTAAAAAGTAATCTC \\
9BPR & ORF528 & + & 16795 & tgcaCTGCAGCGCTTGGTAGTAATTGTA \\
10BPF & ORF527 & - & 12826 & cggGGTACCAAGTGTTTGGATGGTTTGAGCGA \\
10BPR & ORF527 & + & 12050 & tgcaCTGCAGACGTCAATGGGATTACCATTTTCA \\
11BPF & ORF525 & - & 10515 & cggGGTACCGTTTCAATG \\
11BPR & ORF525 & + & 10352 & tgcaCTGCAGCAACCTTGTT \\
$4 \mathrm{BPF}$ & ORF524 & + & 8392 & cggGGTACCGGAAGACTTT \\
$4 \mathrm{BPR}$ & ORF524 & - & 7276 & tgcaCTGCAGACATGAATC \\
\hline
\end{tabular}

* The position refers to the reference sequence from Akopyants et al. (1998).

in a controlled micro-aerophilic atmosphere $\left(8 \% \mathrm{O}_{2} / 10 \%\right.$ $\mathrm{CO}_{2}$ ). Bacteria were transferred onto selective plates and grown in an anaerobic jar. DNA was extracted from the single colonies that appeared after 3-6 days and analysed.

\section{RESULTS}

\section{Status of cag PAl of the $\boldsymbol{H}$. pylori strains used in infection experiments}

We analysed H. pylori strain Iris1 for the structure of the cag PAI by PCR analysis, looking for the presence of $\operatorname{cag} A, \operatorname{cagE}, \mathrm{ORF} 527, \mathrm{ORF} 528$, ORF524 and ORF525 (Table 1). These genes were chosen because they are well distributed over the cag PAI. The presence of an interrupted or uninterrupted cag region was investigated by PCR using primers directed to the region flanking IS605. If IS605 was present, we would expect a band of $2100 \mathrm{bp}$; in the case of fused cagI and cagII regions, the resulting band would be $600 \mathrm{bp}$. Finally, if the intervening sequence divided the two cag regions, the PCR could not be completed because of the size of the fragment to be amplified. Strain Iris1 turned out to be a type I strain $\left(\mathrm{cag}^{+}\right)$with an uninterrupted cag region. Strain SS1, the other strain used in infection experiments, has been shown to have a cag PAI lacking ORF $7\left(\mathrm{cag}^{+} \mathrm{ORF}^{-}\right)$ (Salama et al., 2000; Table 2). From the functional point of view, SS1 has been shown to be unable to induce an IL-8 response (van Doorn et al., 1999).

\section{Construction of $\boldsymbol{H}$. pylori isogenic mutants}

Mutations within the $\operatorname{cagA,~ORF528,~ORF527,~ORF525~}$ and ORF524 genes were constructed in two type I $H$. pylori strains (Iris1 and SS1). After natural transformation, using the appropriate plasmid, each clone was selected by plating on kanamycin blood agar plates. PCR was used to verify that the gene had been inactivated by insertion of the kanamycin cassette using primers mapping on chromosomal DNA just up- and
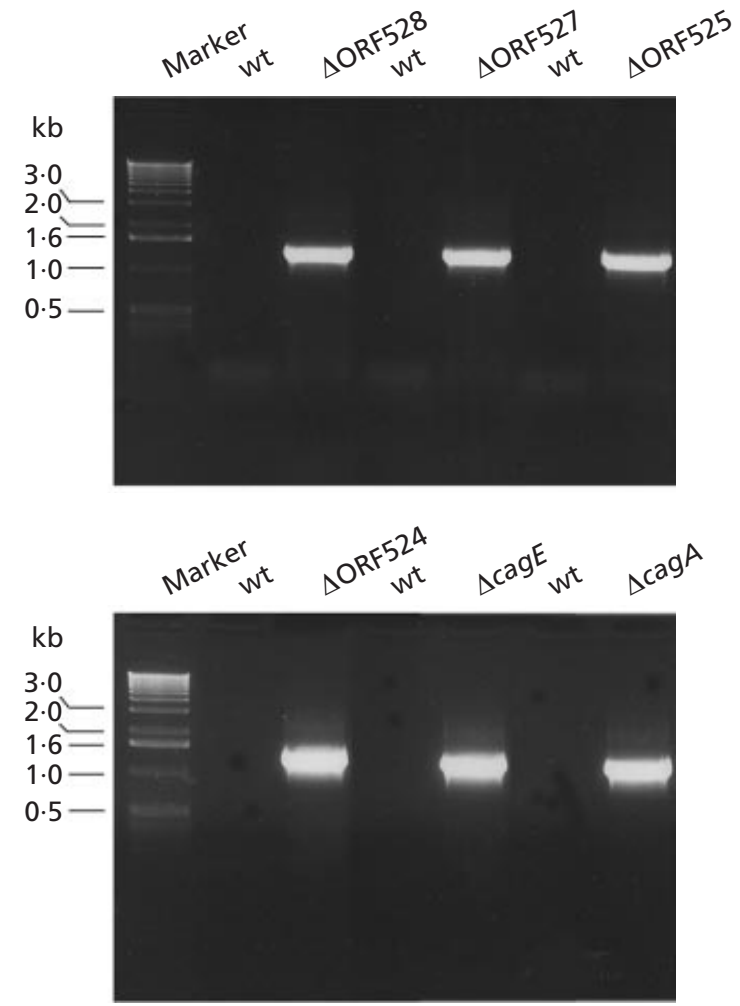

Fig. 1. $P C R$ analysis of the SS1 parent and transformants. Each pair of primers maps just up- and downstream of the cloned kanamycin cassette of each specific gene. For each isogenic mutant we amplified a band of $1400 \mathrm{bp}$ corresponding to the size of the kanamycin cassette, indicating that it had been correctly inserted.

downstream of the kanamycin insertion site in each gene (Table 4). As shown in Fig. 1, each mutant had a PCR product of $1.4 \mathrm{~kb}$, indicating that the gene had been inactivated by the insertion of the kanamycin cassette. 

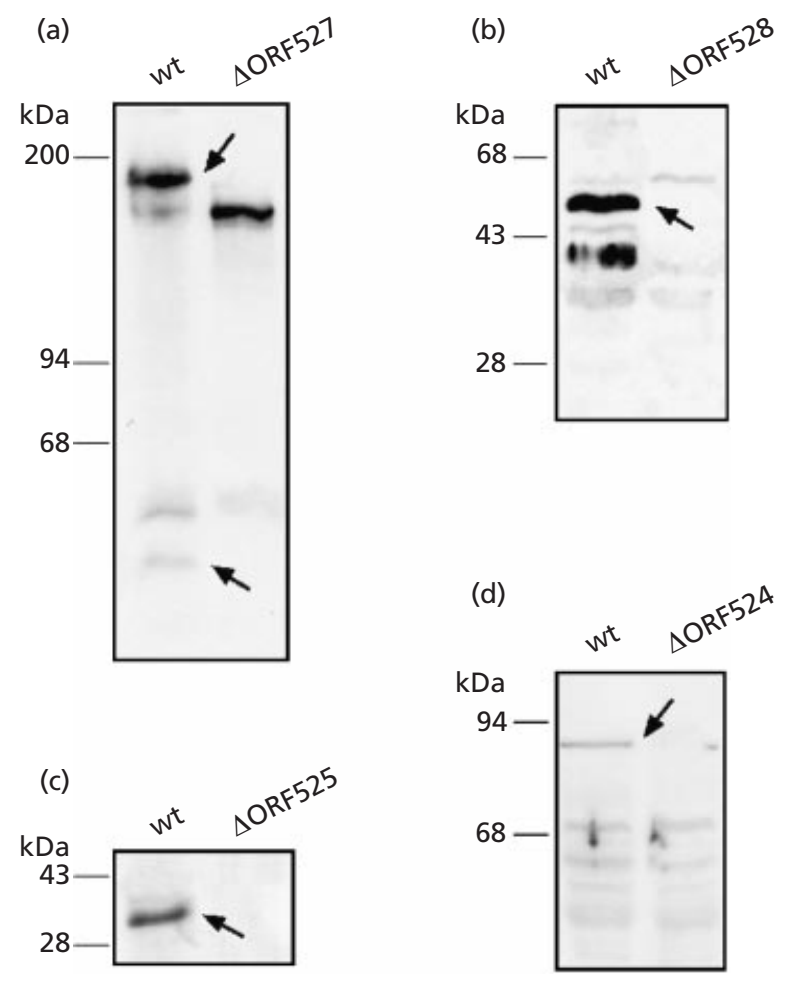

Fig. 2. Immunoblots of ORF527 (a), ORF528 (b), ORF525 (c) and ORF524 (d) proteins in cell extracts of the Iris1 wild-type and the corresponding isogenic mutants. Arrows indicate the band corresponding to the protein recognized by specific polyclonal antibodies.

The recombinant colony, one from each mutant, was then chosen and used for colonization experiments.

\section{Phenotypic characterization of $\boldsymbol{H}$. pylori cag gene mutants}

To test whether the cagA, cagE, ORF528, ORF527, ORF525 and ORF524 mutants had lost the ability to express the antigen encoded by the corresponding gene, we used immunoblot analysis of the whole-cell extracts. In each case, the corresponding antigen was present in the parental strain, but absent from the isogenic mutant. Fig. 2 shows representative immunoblot assays obtained for Iris1. The same results were obtained for SS1 (data not shown). In the case of ORF527, the specific antibodies recognized, as predicted, a $189 \mathrm{kDa}$ band and an additional $36 \mathrm{kDa}$ band. These bands were absent from the $\triangle$ ORF527 mutant (Fig. 2a). In the $\Delta$ ORF527 mutant (Fig. 2a) a lower band was seen. Although we do not have an explanation for this band, we believe it is due to the extreme development of the crossreacting band of similar molecular mass in the wild-type strain. Antibodies raised against the fusion protein for ORF528 identified a $56 \mathrm{kDa}$ protein. This corresponds to the predicted size of the VirB9 protein, which is expressed by the wild-type strain, but not by the $\triangle$ ORF528 mutant (Fig. 2b). Anti-ORF525 antibodies recognized a $32 \mathrm{kDa}$ protein in the wild-type, but not in the mutant (Fig. 2c). Finally, polyclonal antisera obtained by immunizing rabbits with a fusion protein constructed for ORF524 recognized a $90 \mathrm{kDa}$ band in the wild-type bacterial lysate, but not in the isogenic mutant strain (Fig. 2d). To test whether the mutations affected the growth capacity of the organisms, the mutants were cultured in blood agar plates and in liquid medium. The growth capacity of the mutants did not differ when compared to the corresponding wild-type strains (not shown).

\section{Virulence of the isogenic mutants in vivo}

To test the ability of each cag mutant to colonize the stomach of CD1/SPF mice, the six mutants and the corresponding parental strains were used to inoculate 10 mice for each bacterial strain in two independent experiments. The laboratory strain CCUG 17874, that is unable to establish infection (Marchetti et al., 1995), was used as negative control. The SS1 and Iris1 wildtype strains and relative mutant strains had a similar number of in vitro passages before being used for infection experiments to avoid the possibility that repetitive laboratory passages, in particular for the mutant strains, influenced their ability to colonize. Infection was assessed 10 days after the last bacterial inoculum by quantifying the number of bacteria in the stomach of each mouse after homogenization and plating out serial dilutions. As expected, none of the control mice inoculated with the laboratory strain CCUG 17874 were infected. Comparison of the two wild-type strains revealed that the colonization efficiency of SS1 was higher than that of Iris1 (Fig. 3). Infection with Iris1 resulted in approximately $8.9 \times 10^{4}$ c.f.u. (g wet wt gastric mucosa) ${ }^{-1}$, whereas infection with SS1 resulted in three times more c.f.u. $\left[2.5 \times 10^{5}\right.$ c.f.u. (g wet wt gastric mucosa) $\left.{ }^{-1}\right]$. In all the experiments between 90 and $100 \%$ of the mice inoculated with the wild-type strains or with the cag $A$ mutants were infected. Remarkably, only a mean of $20-40 \%$ of the mice inoculated with the other cag mutants were infected (data not shown). The degree of colonization in mice that had been infected with the $\operatorname{cag} A$ mutant was not significantly lower than in the corresponding parental strains. In marked contrast, ablation of the cagE (virB4), ORF527 (virB10) and ORF528 (virB9) genes significantly reduced the number of colonies recovered from infected mice in both strains (Fig. 3). When the Iris $1 \Delta c a g E$ mutant was used a $10^{3}$-fold reduction in infection was observed. Following bacterial inoculation with SS1 1 cagE, we recovered a mean of 90 c.f.u. (g wet wt gastric mucosa) $)^{-1}$ and no colonies were recovered from most of the inoculated mice $(83 \%)$. The level of infection following inoculation with the Iris1 $\triangle$ ORF528 (virB9) mutant strain was about 1000 -fold lower than with the corresponding wild-type. The colonization rate of SS1 1 ORF528 was approximately 1300 -fold lower $\left[1.9 \times 10^{2}\right.$ vs $2.5 \times 10^{5}$ c.f.u. (g wet wt gastric mucosa) $\left.{ }^{-1}\right]$ than that of the corresponding wild-type. When ORF527 (virB10) was mutated the number of colonies recovered 

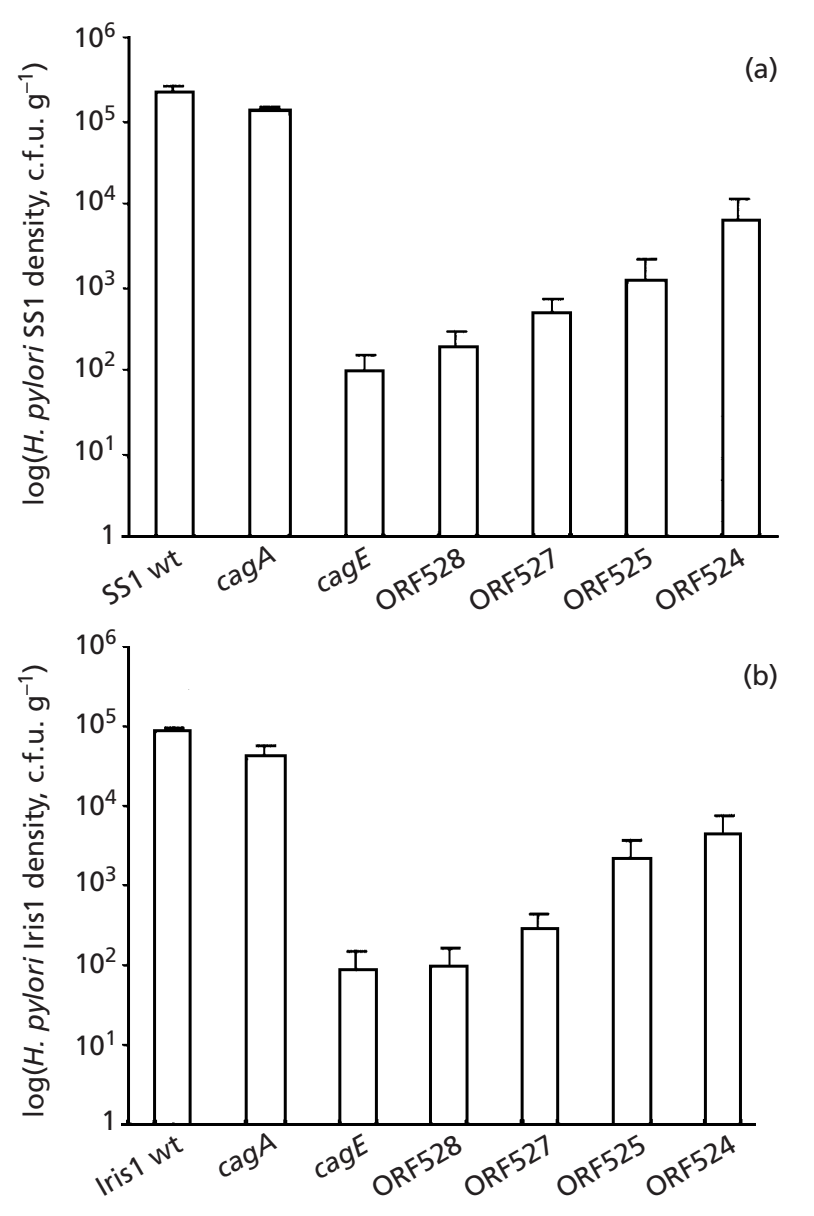

Fig. 3. Colonization phenotype of the $H$. pylori wild-type strains and isogenic mutants. Groups of mice were infected and then killed 10 days after infection. Half of the stomach from each mouse was homogenized and dilutions plated on blood agar plates. The values shown represent the c.f.u. recovered. Results were obtained with SS1 (a) and Iris1 (b) and the corresponding isogenic mutants, respectively. Each value is the mean \pm SD of all mice that received the same bacterial inoculum in two independent experiments.

was approximately 1000 -fold lower for the SS1 mutant and 300-fold lower for the Iris1 mutant than for the corresponding wild-type strains. The colonization efficiency of the SS1 $1 \Delta$ ORF525 mutant was approximately 200 -fold lower than that of the corresponding parental strain. The colonization efficiency of SS1 $\triangle$ ORF524 (virD4) was 40 times lower than in the wild-type and that of the Iris1 mutant was about 20 times lower.

\section{Assessment of colonization by PCR}

The infection experiments revealed that the number of mice infected with the cag mutant strains, except for $\operatorname{cag} A$, was always lower than the number of mice infected with the wild-type strains. Thus, we decided to use a more sensitive system to reveal the presence of very small numbers of infecting organisms. Chromosomal DNA was extracted from the gastric tissue of infected
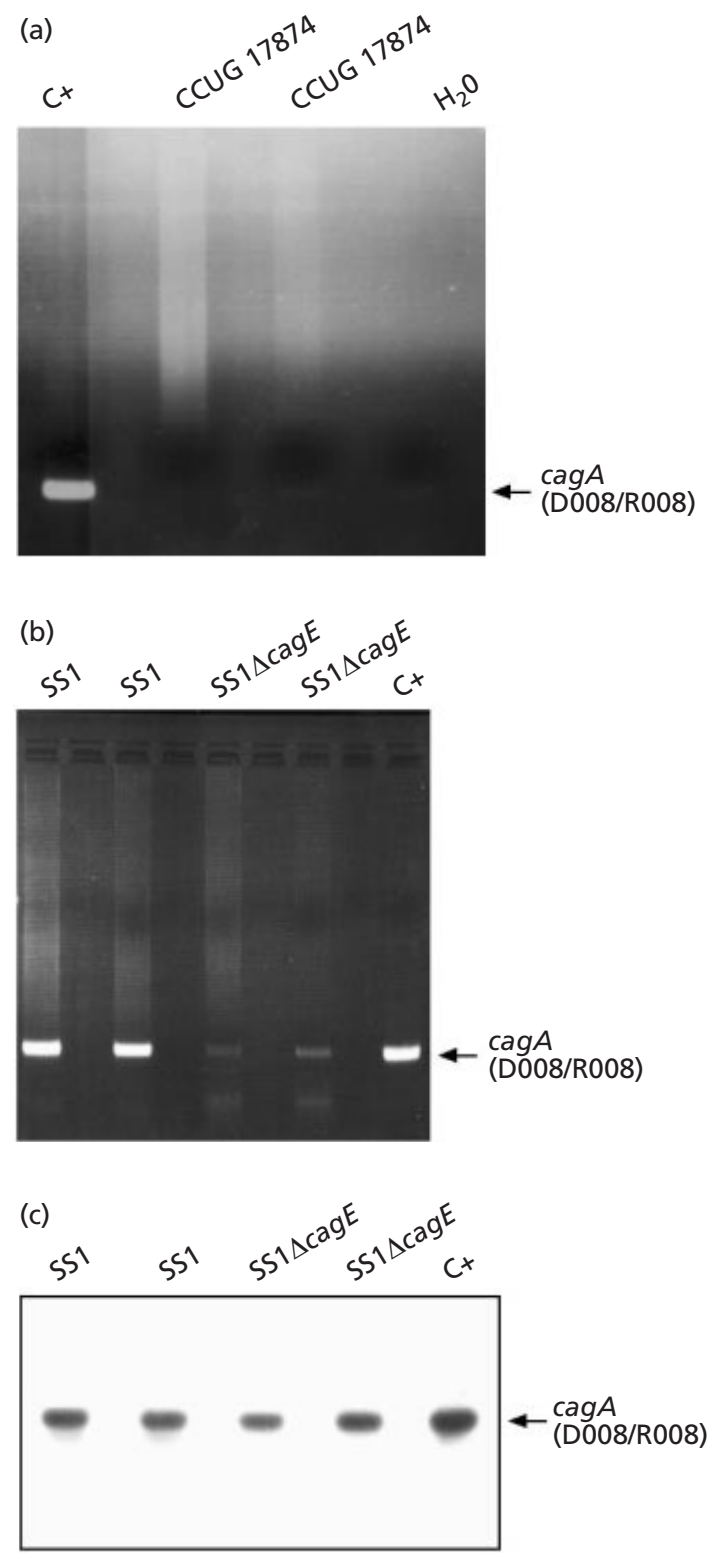

Fig. 4. Assessment of colonization by $P C R$. $P C R$ was performed on DNA extracted from the homogenized tissue of half of the stomach of infected mice (see Methods). Specific primers for cagA were used (D008/R008). (a) PCR on mice infected with the $H$. pylori CCUG 17874. (b) Representative PCR on mice inoculated with SS1 wild-type and SS1 $\Delta$ cagE; in this case the amplification was used for Southern blotting with a cagA probe (c). SS1 DNA was used as positive control (C+).

animals (see Methods) and PCR was performed with primers specific for $\operatorname{cagA}$ (D008/R008) (Xiang et al., 1995; Table 1). Fig. 4 shows the results obtained after analysing the stomachs of two representative mice infected with SS1 and positive for colony recovery and the isogenic mutant SS1 $\Delta$ cagE in which we could not recover any colonies on plates. Mice inoculated with the laboratory strain CCUG 17874 were used as control because this strain is unable to infect mice. From the 
gastric tissue of half a mouse stomach we could always recover approximately $100 \mu \mathrm{g} \mathrm{DNA} \mathrm{ml}^{-1}$ and $100 \mathrm{ng}$ was used for PCR amplification. As expected, we did not get any PCR product from mice that received strain CCUG 17874, confirming that this laboratory strain cannot infect mice (Fig. 4a). When we analysed mice infected with SS1 and the $\Delta$ cagE mutant, we found that all the mice sacrificed 10 days after infection gave a positive signal (Fig. 4b) and that the band was stronger for mice inoculated with wild-type SS1 than for those that received the $\triangle$ cagE mutant. We also performed Southern blot hybridization using cagA as probe to confirm that the PCR reaction was specific (Fig. 4c). This indicated that in these mice the infection was strongly reduced, but not abolished, and that the low number of infecting organisms could be detected only by this more sensitive system.

\section{DISCUSSION}

Since their discovery, PAIs have generated great interest and they have been described in an increasing number of pathogens (Springer \& Goebel, 1980; Hacker et al., 1997). In 1996, a pathogenicity island was identified in the human gastric pathogen H. pylori (Censini et al., 1996). On the basis of the presence or absence of the cag PAI, H. pylori strains are now grouped in two large families: type I and type II, respectively (Censini et al., 1996; Akyopants et al., 1998). The presence of cag PAI in the bacterial genome is associated with more severe clinical outcomes (Telford et al., 1994; Marchetti et al., 1995). Moreover, its product is homologous to components of the multiprotein complexes found in $A$. tumefaciens and B. pertussis (type IV secretion system), and it is necessary for the delivery of the CagA protein into epithelial gastric cells in vitro (Segal et al., 1999; Odenbreit et al., 2000; Stein et al., 2000).

We selected two strains: Iris1, isolated by us from a clinical sample, and SS1, well described in literature. Both of them are $\mathrm{Cag}^{+}$as demonstrated by genetic analysis with SSI lacking ORF7. These two H. pylori strains were used in our experimental infections and the colonization phenotype of the cagA, cagE, ORF528, ORF527, ORF525 and ORF524 mutants has been assessed in the mouse model of infection. The results show that these genes can influence bacterial colonization in our mouse model of infection. The mutants did not show significant differences in growth under laboratory conditions, suggesting that the observed phenotype is strictly in vivo-dependent. The colonization phenotype was assessed during the early stages of infection, 10 days after inoculation. This time was chosen according to the results obtained for non-motile flagellin mutant strains, showing that a time shorter than 10 days could give false results for the bacterial colonization phenotype (Eaton et al., 1996; Kim et al., 1999). The colonization of the cag mutants normalized following a longer infection period (data not shown). This is consistent with the results obtained by Eaton $e t$ al. (2001) and Ogura et al. (2000) and suggests that the reduced colonization density observed for the cagE, ORF528, ORF527, ORF525 and ORF524 mutants could be related to the function(s) that these components may play in the initial step of the colonization process. However, the mechanism responsible for the observed phenotype is not known. We showed that the inactivation of these cag genes did not abolish infection but that it was sufficient to diminish their ability to establish infection. The inactivation of the cag genes may disrupt the cag system, thus reducing bacterial virulence. As a consequence, bacteria need more time before they recover their normal colonization efficiency. However, not all of the cag genes are involved in the observed phenotype, and mutations of $\operatorname{cag} A$, encoding the secreted protein CagA, did not significantly affect the bacterial density. This observation is consistent with previous findings that demonstrated that $\operatorname{cag} A$ mutants are able to infect animal models with the same efficiency as the wild-type strain (Wirth et al., 1998).

Considering the short time course of infection, we could not expect any histopathological change in the gastric tissue of mice infected with the wild-type or with the mutant strains. Other studies have shown that gastritis induced by wild-type strains is similar to that induced by H. pylori cagA mutants in the first weeks of infection (Ghiara \& Marchetti, 1998). Two H. pylori strains were used in parallel in the infection experiments. Mutants for the same genes in all the wild-type strains showed a comparable colonization phenotype. This suggests that the in vivo cag-dependent phenotype is independent of the bacterial genetic background.

In conclusion, we have shown that the presence of $c a g$, at least for some of the cag genes, increases the ability of type I strains to colonize the stomach of mice. The mechanisms involved and the pathological traits associated with these cag genes in vivo remain unknown.

\section{ACKNOWLEDGEMENTS}

We thank A. Covacci for helpful discussion and important advice. We acknowledge S. Censini for helping in mutant construction. We thank M. Gori and A. Muzzi for oligonucleotide synthesis and S. Guidotti for automated sequencing. G. Corsi is very gratefully acknowledged for artwork. We thank S. Pasquini, L. Fini and S. Ciabattini for preparing the bacterial medium. We gratefully acknowledge M. Tortoli and A. Matteucci for animal care. M.M. is a recipient of a grant from the European Union HPMF-CT1999-00379.

\section{REFERENCES}

Akopyants, N. S., Clifton, S. W., Kersulyte, D. \& 7 other authors (1998).Protein analyses of the cag pathogenicity island of Helicobacter pylori. Mol Microbiol 28, 37-53.

Atherton, J. C., Cao, P., Peek, R. M., Tumurru, M., Blaser, J. \& Cover, T. L. (1995). Mosaicism in vacuolating cytotoxin alleles of Helicobacter pylori. Association of specific vacA types with cytotoxin production and peptic ulceration. J Biol Chem 270, 17771-17777. 
Blaser, M. J. (1992). Helicobacter pylori: its role in disease. Clin Infect Dis 15, 386-391.

Censini, S., Lange, C., Xiang, Z., Crabtree, J. E., Ghiara, P., Borodovsky, M., Rappuoli, R. \& Covacci, A. (1996). cag, a pathogenicity island of Helicobacter pylori, encodes type Ispecific and disease-associated virulence factors. Proc Natl Acad Sci U S A 93, 14648-14653.

Christie, P. J. (1997). Agrobacterium tumefaciens T-complex transport apparatus: a paradigm for a new family of multifunctional transporters in eubacteria. J Bacteriol 179, 3085-3094.

Clayton, C., Kleanthous, K. \& Tabaqchali, S. (1991). Detection and identification of Helicobacter pylori by the polymerase chain reaction. J Clin Pathol 44, 515-516.

Copass, M., Grandi, G. \& Rappuoli, R. (1997). Introduction of unmarked mutation in the Helicobacter pylori vacA gene with a sucrose sensitivity marker. Infect Immun 65, 1949-1952.

Eaton, K. A., Suerbaum, S., Josenhans, C. \& Krakowka, S. (1996). Colonization of gnotobiotic piglet by Helicobacter pylori deficient in two flagellin genes. Infect Immun 64, 2445-2448.

Eaton, K. A., Kersulyte, D., Mefford, M., Danon, S. J., Krakowka, S. \& Berg, D. E. (2001). Role of Helicobacter pylori cag region genes in colonization and gastritis in two animal models. Infect Immun 69, 2902-2908.

Ghiara, P. \& Marchetti, M. (1998). Strategies for preventive and therapeutic vaccination against Helicobacter pylori infection. Symp Immunol VII, 109-126.

Glocker, E., Lange, C., Covacci, A., Bereswill, S., Kist, M. \& Pahl, H. L. (1998). Proteins encoded by the cag pathogenicity island of Helicobacter pylori are required for NF-kappaB activation. Infect Immun 66, 2346-2348.

Hacker, J., Blum-Oehler, G., Muhldorfer, I. \& Tschape, H. (1997). Pathogenicity islands of virulent bacteria: structure, function and impact on microbial evolution. Mol Microbiol 23, 1089-1097.

Karita, M., Kouchiyama, T., Okita, K. \& Nakazawa, T. (1991). New small animal model for human gastric Helicobacter pylori infection: success in both nude and euthymic mice. Am J Gastroenterology 86, 1596-1603.

Kim, J. S., Chang, J. H., Chung, S. I. \& Yum, J. S. (1999). Molecular cloning and characterization of the Helicobacter pylori fliD gene, an essential factor in flagellar structure and motility. J Bacteriol 181, 6969-6976.

Kyte, J. \& Doolittle, R. F. (1982). A simple method for displaying the hydropathic character of a protein. J Mol Biol 157, 105-132.

Lee, A. (1998). Animal models for host-pathogen interaction studies. Br Med Bull 54, 163-173.

Lee, A., O'Rourke, J., De Ungria, M. C., Robertson, B., Daskalopoulos, G. \& Dixon, M. F. (1997). A standardized mouse model of Helicobacter pylori infection: introducing the Sydney strain. Gastroenterology 4, 1386-1397.

Logan, R. P. H. (1994). Helicobacter pylori and gastric cancer. Lancet 344, 1078-1079.

Marchetti, M., Arico, B., Burroni, D., Figura, N., Rappuoli, R. \& Ghiara, P. (1995). Development of a mouse model of Helicobacter pylori infection that mimics human disease. Science 267, 16551658.

Mitchell, H. M. (1993). The epidemiology of Helicobacter pylori infection and its relation to gastric cancer. In Helicobacter pylori: Biology and Clinical Practice, pp. 95-114. Edited by C. S. Goodwin \& B. W. Wormsley. Boca Raton, FL: CRC Press.

NIH consensus (1994). Development panel on Helicobacter pylori in peptic ulcer disease. JAMA 272, 65-69.
O'Callaghan, D., Cazevieille, C., Allardet-Servent, A., Boschiroli, M. L., Bourg, G., Foulongne, V., Frutos, P., Kulakov, Y. \& Ramuz, M. (1999). A homologue of the Agrobacterium tumefaciens VirB and Bordetella pertussis Ptl type IV secretion systems is essential for intracellular survival of Brucella suis. Mol Microbiol 6, 1210-1220.

Odenbreit, S., Puls, J., Sedhmarie, B., Gerland, E., Fisher, W. \& Haas, R. (2000). Translocation of Helicobacter pylori CagA into gastric epithelial cell by type IV secretion. Science 287, 1497-1500.

Ogura, K., Maeda, S., Nakao, M., Watanabe, T., Tada, M., Kyutoku, T., Yoshida, H., Shiratori, Y. \& Omata, M. (2000). Virulence factors of Helicobacter pylori responsible for gastric diseases in Mongolian gerbil. J Exp Med 192, 1601-1609.

Pagliaccia, C., De Bernard, M., Lupetti, P. \& 7 other authors (1998). The $\mathrm{m} 2$ form of the Helicobacter pylori cytotoxin has cell type-specific vacuolating activity. Proc Natl Acad Sci US A 95, 10212-10217.

Parsonnet, J., Friedman, G. D., Vandersteen, D. P., Chang, Y., Vogelman, J. H., Orentreich, N. \& Sibley, R. K. (1991). Helicobacter pylori infection and the risk of gastric carcinoma. N Engl J Med 325, 1127-1131.

Reeves, P. J., Douglas, P. \& Salmond, G. P. (1994). $\beta$-Lactamase topology probe analysis of the OutO NMePhe peptidase, and six other Out protein components of the Erwinia carotovora general secretion pathway apparatus. Mol Microbiol 12, 445-457.

Salama, N., Guillemin, K., McDaniel, T. K., Sherlock, G., Tompkins, L. \& Falkow, S. (2000). A whole-genome microarray reveals genetic diversity among Helicobacter pylori strains. Proc Natl Acad Sci U S A 97, 14668-14673.

Segal, E. D., Lange, C., Covacci, A., Tompkins, L. S. \& Falkow, S. (1997). Induction of host signal transduction pathways by Helicobacter pylori. Proc Natl Acad Sci U S A 94, 7595-7599.

Segal, E. D., Cha, J., Lo, J., Falkow, S. \& Tompkins, L. S. (1999). Altered states: involvement of phosphorylated CagA in the induction of host cellular growth changes by Helicobacter pylori. Proc Natl Acad Sci US A 96, 4559-4564.

Segal, G. \& Shuman, H. A. (1999). Possible origin of the Legionella pneumophila virulence genes and their relation to Coxiella burnetii. Mol Microbiol 33, 669-700.

Springer, W. \& Goebel, W. (1980). Synthesis and secretion of hemolysin by Escherichia coli. J Bacteriol 144, 53-59.

Stein, M., Rappuoli, R. \& Covacci, A. (2000). Tyrosine phosphorylation of the Helicobacter pylori CagA antigen after cag-driven host cell translocation. Proc Natl Acad Sci U S A 97, 1263-1268.

Telford, J. L., Ghiara, P., Dell'Orco, M. \& 11 other authors (1994). Gene structure of the Helicobacter pylori cytotoxin and evidence of its key role in gastric disease. J Exp Med 179, 1653-1658.

Tomb, J. F., White, O., Kerlavage, A. R. \& 38 other authors (1997). The complete genome sequence of the gastric pathogen Helicobacter pylori. Nature 388, 539-547.

Van Doorn, N., Namavar, F., Sparrius, M., Stoof, J., van Rees, E. P., van Doorn, L. J. \& Vandenbroucke-Grauls, C. M. E. (1999). Helicobacter pylori-associated gastritis in mice is host and strain specific. Infect Immun 67, 3040-3046.

Villarejo, M. R. \& Zabin, I. (1974). $\beta$-Galactosidase from termination and deletion mutant strains. J Bacteriol 120, 466-474.

Vogel, J. P., Andrews, H. L., Wong, S. K. \& Isberg, R. R. (1998). Conjugative transfer by the virulence system of Legionella pneumophila. Science 279, 873-876.

Weiss, A. A., Johnson, F. D. \& Burns, D. L. (1993). Molecular characterization of an operon required for pertussis toxin secretion. Proc Natl Acad Sci U S A 90, 2970-2974. 
Winans, S. C., Burns, D. L. \& Christie, P. J. (1996). Adaptation of a conjugal transfer system for the export of pathogenic macromolecules. Trends Microbiol 4, 64-68.

Wirth, H. P., Beins, M. H., Yang, M., Tham, K. T. \& Blaser, M. J. (1998). Experimental infection of Mongolian gerbils with wildtype and mutant Helicobacter pylori strains. Infect Immun 66, 4856-4866.

Xiang, Z., Censini, S., Bayeli, P. F., Telford, J. L., Figura, N., Rappuoli, R. \& Covacci, A. (1995). Analysis of expression of CagA and VacA virulence factors in 43 strains of Helicobacter pylori reveals that clinical isolates can be divided into two major types and that CagA is not necessary for expression of the vacuolating cytotoxin. Infect Immun 63, 94-98.

Zupan, J. R., Ward, D. \& Zambryski, P. (1998). Assembly of the VirB transport complex for DNA transfer from Agrobacterium tumefaciens to plant cells. Curr Opin Microbiol 1, 649-655.

Received 19 July 2001; revised 18 January 2002; accepted 21 January 2002. 